\title{
FAKTOR PENGHAMBAT KERAJINAN ANYAMAN TANGAN DI PERBATASAN SAJINGAN BESAR DALAM MENGHADAPI MASYARAKAT EKONOMI ASEAN
}

\author{
A. Razak ${ }^{1}$ dan Elyta ${ }^{2}$ \\ ${ }^{1}$ Politeknik Negeri Pontianak \\ ${ }^{2}$ Fakultas Ilmu Sosial dan Ilmu Politik Universitas Tanjungpura \\ E-mail: razakalkadrie@yahoo.co.id
}

\begin{abstract}
ABSTRAK. Salah satu kerajinan anyaman tangan Kalimantan Barat berasal dari perbatasan Sajingan Besar Kabupaten Sambas, kerajinan anyaman tangan tersebut merupakan warisan secara turun temurun yang membutuhkan pembinaan melalui inovasi dari regenerasi baru. Tujuan penelitian ini adalah untuk melihat faktor-faktor penghambat dalam mengembangkan kerajinan anyaman tangan masyarakat di Perbatasan Sajingan Besar. Metode penelitian ini menggunakan analisis kualitatif, peneliti melakukan wawancara dari berbagai informan dan mengumpulkan data sekunder dari instansi terkait. Hasil penelitian menunjukkan terdapat dua faktor penghambat pengembangan kerajinan anyaman tangan di wilayah perbatasan Sajingan Besar Kabupaten Sambas dalam menghadapi Masyarakat Ekonomi ASEAN yaitu: 1) pola pikir masyarakat kurang inovatif dikarenakan kurangnya lembaga pendidikan dan pembinaan anyaman kerajinan untuk masyarakat sehingga kerajinan anyaman tangan sulit berkembang; 2) pemasaran produktifitas kerajinan anyaman tangan terkendala karena belum diresmikannya Pos Lintas Batas Negara Aruk di Kabupaten Sambas. Rendahnya kualitas sumber daya manusia membuat pelaksanaan Masyarakat Ekonomi ASEAN tidak terlalu dirasakan oleh masyarakat perbatasan Sajingan Besar Kabupaten Sambas dan kurangnya pemasaran mengakibatkan produk kerajinan anyaman tangan di wilayah perbatasan Sajingan Besar Kabupaten Sambas sulit bersaing dalam menghadapi Masyarakat Ekonomi ASEAN.
\end{abstract}

Kata kunci: kerajinan anyaman tangan, penghambat, Masyarakat Ekonomi ASEAN

\section{THE RESISTOR FACTORS OF HANDICRAFTS IN SAJINGAN BESAR BORDER AGAINTS ASEAN ECONOMIC COMMUNITY}

\begin{abstract}
One of hand crafting West Kalimantan handicraft comes from the border of Sajingan Besar Sambas Regency. Handicraft is a hereditary heritage that requires continuous coaching through innovation of tire regeneration. The purpose of this study is to see the resistor factors in developing hand-woven handicrafts community in Border Sajingan Besar This research method using qualitative analysis, researchers conducted interviews from various informants and collect secondary data from relevant agencies. The result of the research shows that there are two resistor factors the development of hand-woven handicrafts in the border area of Sajingan Besar Sambas Regency in facing the ASEAN Economic Community, namely: 1) the mindset of the community is less innovative due to the lack of educational institutions and the craftsmanship of handicrafts for the community so that hand-crafting is difficult to develop; 2) marketing the productivity of hand crafted handicrafts constrained because it has not been inaugurated the Boundary Post Aruk State Border in Sambas District. The low quality of human resources makes the implementation of ASEAN Economic Community is not too felt by the border community Sajingan Besar Sambas district and the lack of marketing resulted in hand-woven handicraft products in the border region of Sajingan Besar Sambas difficult to compete in facing the ASEAN Economic Community.
\end{abstract}

Key words: handicraft, resistor, ASEAN Economic Community

\section{PENDAHULUAN}

Kearifan anyaman lokal telah diwariskan secara turun temurun, produk kerajinan budaya tercipta dari sebuah konsep sejarah atau cerita rakyat yang dituangkan dalam berbagai jenis karya seni (Rice, 2016: 239). Salah satu karya seni budaya adalah jenis anyaman yang dihasilkan dari wilayah perbatasan Kabupaten Sambas khususnya Kecamatan Sajingan Besar. Anyaman tersebut berasal dari pandan, bambu, rotan dan pita plastik. Perbatasan Sajingan Besar Kabupaten Sambas memiliki sumber daya yang berpotensi untuk mengolah kerajinan anyaman tangan.

Produksi kerajinan anyaman tangan berupa anyaman tikar terdapat di 4 Kelurahan yang ada Kecamatan Sajingan Besar Kabupaten Sambas yaitu
Kelurahan Kaliau, Kelurahan Sentaban, Kelurahan Sei Bening dan Kelurahan Senatab (Badan Pusat Statistik Kabupaten Sambas, 2016: 68). Masyarakat yang mengerjakan anyaman tersebut adalah kalangan usia yang sudah tua renta, sedangkan generasi muda jarang untuk ikut berpartisipasi. Kegiatan menganyam hanya digunakan masyarakat untuk mengisi waktu luang sehingga profesi tersebut sebatas untuk memanfaatkan waktu luang. Masyarakat perbatasan Sajingan Besar Kabupaten Sambas terlihat mengolah kerajinan anyaman tangan tanpa menargetkan jumlah produksi.

Kerajinan anyaman tangan Kalimantan Barat yang berasal dari Sajingan Besar Kabupaten Sambas diwariskan oleh leluhur nenek moyang. Kelestarian kerajinan anyaman tangan disinyalir kurang partisipasi dari generasi baru. Salah satu bentuk partisipasi tersebut 
melalui inovasi produk anyaman misalnya kreatifitas dari segi model dan warna. Pengembangan ide kreatif dan pola pikir masyarakat memegang peranan terhadap kerajinan anyaman tangan ke generasi penerusnya secara turun-menurun.

Terlihat barang hasil produksi kerajinan anyaman tangan dari perbatasan Indonesia di jual ke negara Malaysia, namun belum ada lembaga khusus yang menjadi wadah pemasaran bagi pengrajin anyaman, padahal produk kerajinan anyaman di perbatasan Sajingan Besar Kabupaten Sambas memiliki peluang dan berpotensi besar mengingat wilayah perbatasan berbatasan langsung dengan Negara Malaysia. Lebih lanjut disinyalir pemasarannya masih terkendala pada proses ekspor sehingga produk anyaman belum maksimal untuk di ekspor keluar negeri terutama di Negara Malaysia. Terlihat lalu lintas perdagangan belum memanfaatkan Pos Lintas Batas Negara (PLBN) Aruk. Hal ini disinyalir membuat ekspor produk kerajinan tangan anyaman kurang produktif dan distributif.

Jumlah usaha industri kecil kerajinan anyaman tangan di Kecamatan Sajingan Besar Kabupaten Sambas dari tahun 2008 hingga 2015 tidak mengalami perkembangan. Jumlah industri kecil kerajinan anyaman tangan hanya sebanyak 2 industri kecil (Badan Pusat Statistik Kabupaten Sambas, 2016: 67). Selanjutnya, Masyarakat Ekonomi ASEAN (MEA) terdiri dari negaranegara anggota Association of South East Asia Nation (ASEAN). MEA dibentuk untuk dijadikan sebagai pasar produksi tunggal di kawasan ASEAN. Selain itu terbentuknya ASEAN agar aktivitas perdagangan menjadi lebih dinamis dan mampu bersaing. Kerjasama ASEAN memperkokoh hubungan antar negara yang didalamnya terdapat inisiatif ekonomi yang dapat memperlancar integrasi regional khususnya di kawasan perbatasan Sajingan Besar Kabupaten Sambas dalam mengembangkan anyaman kerajinan tangan. Kontribusi kerajinan anyaman tangan sebagai potensi ekonomi lokal belum memberikan pengaruh yang signifikan terhadap tingkat penyerapan tenaga kerja, produktivitas daerah, dan pendapatan asli daerah. Disinyalir Pemerintah Daerah juga belum serius memberdayakan potensi para pengrajin untuk segera meresmikan PLBN Aruk di Kabupaten Sambas sebagai pintu masuk perdagangan kedua negara. Berdasarkan fenomena-fenomena tersebut peneliti tertarik untuk meneliti faktor-faktor yang menghambat pengembangan anyaman kerajinan tangan di wilayah perbatasan Sajingan Besar Kabupaten Sambas untuk menghadapi MEA.

\section{METODE}

Penelitian ini menggunakan metode analisis deskriptif kualitatif. Lokasi penelitian dilakukan di wilayah perbatasan Sajingan Besar Kabupaten Sambas. Peneliti memperoleh informasi secara langsung di lapangan dengan mewawancarai beberapa informan secara mendalam yaitu Kepala Bagian Pengelolaan Perbatasan Sekretariat Daerah kabupaten Sambas, Kepala Seksi Kerajinan Kimia dan Aneka Industri Kabupaten Sambas Dinas Perdagangan dan Perindustrian Kabupaten Sambas, Kepala Desa Kaliau, 4 orang pengrajin anyaman tangan dan 2 tokoh masyarakat Sajingan Besar. Peneliti juga menggunakan data sekunder yaitu berupa data dari kantor Badan Pusat Statistik Provinsi Kalimantan Barat, buku dan jurnal.

\section{HASIL DAN PEMBAHASAN}

\section{Faktor Penghambat Pengembangan Produktifitas Kerajinan Anyaman Tangan}

Budaya adalah seperangkat tradisi budaya seperti sastra, seni, dan pendidikan (Nye, 2008: 96). Salah satu budaya dalam bentuk seni adalah kerajinan anyaman tangan Eksistensi kerajinan anyaman tangan dapat dijaga melalui beberapa aspek yaitu meningkatkan keahlian masyarakat perbatasan melalui pelatihan kursus maupun dengan memberikan ekskul di bidang pengrajin dikalangan pelajar sebagai regenerasi baru untuk memproduksi kerajinan anyaman tangan secara berkelanjutan dan inovatif.

Hasil penelitian menunjukkan bahwa berdasarkan penggolongan Badan Pusat Statistik Kalimantan Barat tahun 2015, klasifikasi industri menurut jumlah tenaga kerja di Kecamatan Sajingan Besar Kabupaten Sambas termasuk pada golongan industri rumah tangga karena jumlah tenaga kerja kerajinan anyaman tangan di perbatasan Sajingan Besar Kabupaten Sambas rata-rata berjumlah dua orang.

\section{Pola Pikir Masyarakat Kurang Inovatif}

Inovasi menyebabkan warisan budaya tradisi mengalami perubahan dari kemurnian aslinya (Jeniarto, 2013: 25). Suatu negara tidak terlepas dari risalah artefak, teks-teks sastra dan bentuk peninggalan tradisi kebudayaan (Smith, 2016:1). Anyaman merupakan seni kerajinan yang berasal dari bahan dasar pandan, rotan dan bambu, namun saat ini bahan dasar anyaman lebih banyak menggunakan bahan dasar pita plastik.

Hasil penelitian menunjukkan kerajinan anyaman tangan masyarakat perbatasan Sajingan Besar Kabupaten Sambas masih terkendala pada kurangnya pembinaan dan pola pikir masyarakat yang berbeda. Kebiasaan masyarakat perbatasan Sajingan Besar Kabupaten Sambas saat ini lebih tertarik untuk menggunakan produk dengan cara membeli dari pada memproduksi. Penciptaan produk anyaman terutama pada produk dengan inovasi baru jarang ditemui dan belum memiliki sistem pasar yang jelas. Anyaman bambu, rotan, pandan dan pita plastik kurang mendapatkan sentuhan inovasi produk yang lebih beragam, anyaman lebih banyak pada jenis mebel misalnya rotan yang dianyam menjadi kursi, meja dan perabotan lainnya. 
Lebih lanjut hasil penelitian menunjukkan bahwa kendala masyarakat perbatasan Sajingan Besar Kabupaten Sambas dalam memproduksi kerajinan anyaman adalah mengubah pola pikir masyarakat yang berbeda dengan cara berfikir lebih tertarik untuk membeli daripada memproduksi kerajinan anyaman tangan. Selain itu sebagian masyarakat yang memproduksi kerajinan anyaman tangan sudah cukup puas jika produknya laku terjual dan cukup untuk makan saja. Merubah pola pikir masyarakat tidak hanya dalam hitungan hari dan bulan, proses tersebut memerlukan waktu hingga bertahuntahun. Selain itu masyarakat perbatasan Sajingan Besar Kabupaten Sambas beranggapan sulit untuk melakukan kerja sama karena merasa takut kalah dalam persaingan perdagangan, padahal usaha sejenis itu tidak hanya menjadi saingan namun menjadi rekan kerja.

Adat tradisi dalam suatu kebudayaan masyarakat menciptakan nilai kesenian (Grimes, 2014: 250). Hasil penelitian menemukan bahwa kurangnya minat masyarakat perbatasan untuk memproduksi kerajinan anyaman tangan dikarenakan generasi baru di wilayah perbatasan Sajingan Besar Kabupaten Sambas menganggap bahwa pekerjaan sebagai pengrajin anyaman sudah ketinggalan sehingga mereka tidak tertarik untuk menekuni kerajinan anyaman tangan. Menanggapi hal tersebut mata pelajaran pendidikan kesenian kerajinan anyaman dibutuhkan untuk selipkan pada mata pelajaran, sehingga secara tidak langsung murid-murid akan mempelajari kerajinan anyaman. Hal tersebut bertujuan agar menghindarkan masyarakat perbatasan khususnya generasi muda dari keterasingan nilai budaya kearifan lokal melalui anyaman kerajinan sehingga kebudayaan tersebut tetap dapat dilestarikan sebagai identitas negara.

Kebudayaan menggali potensial identitas suatu negara melalui promosi budaya, untuk mempertahankan eksistensi kebudayaan negara (Nye, 2008: 95). Setiap daerah-daerahmemilikipotensi-potensiyang ditonjolkan berdasarkan dengan hasil kerja. Pada dasarnya terdapat lembaga khusus yang dibentuk oleh masyarakat untuk mengelola kerajinan anyaman di perbatasan Sajingan Besar Kabupaten Sambas. Lembaga tersebut dijadikan sebagai sekolah pengrajin. Sedangkan lembaga pusat yang memberdayakan anyaman di tingkat Kabupaten masih belum tersedia. Selain pemberian mata pelajaran ataupun bentuk ekskul tentang kerajinan anyaman, keberadaan lembaga memiliki peranan penting untuk menjadi wadah pelatihan kerajinan anyaman tangan masyarakat perbatasan Sajingan Besar Kabupaten Sambas. Menurut hasil penilaian Dinas Perindustrian dan Perdagangan Kabupaten Sambas. Saat ini anyaman sudah tidak termasuk dalam produk unggulan. Produk anyaman dinilai kurang memberikan inovasi sehingga produk unggulan beralih menjadi produk-produk lain yang menjadi unggulan.

Hasil penelitian menemukan bahwa kerajinan anyaman tangan di Sajingan Besar Kabupaten Sambas kurang inovatif. Hal tersebut dibuktikan dengan produk kerajinan anyaman tangan Sajingan Besar masih belum mampu menyaingi kerajinan anyaman tangan yang diproduksi dari Jawa yang masuk ke wilayah perbatasan, sehingga kerajinan anyaman tangan produk jawa memiliki harga yang lebih tinggi dibanding dengan kerajinan anyaman tangan produk dari Sajingan Besar. Meskipun memiliki harga yang relatif lebih mahal anyaman tersebut tetap laku karena model anyaman rotan Jawa lebih inovatif. Anyaman yang berasal dari jawa memadukan antara rotan dan busa untuk menambah nilai anyaman. Model tersebut membuat keunikan tersendiri dan kenyamanan bagi pembeli. Sedangkan anyaman lokal yang masih berbentuk polos seperti anyaman zaman kurang diminati para pembeli.

Negara menata sistem yang saling berhubungan, baik hubungan di dalam maupun di luar negeri untuk mencapai kemakmuran (MacIver, 1962:22). MEA merupakan suatu bentuk kerja sama perdagangan baik berupa barang maupun jasa antar negara-negara di kawasan ASEAN. MEA memiliki tujuan untuk meningkatkan perekonomian di kawasan Asia Tenggara khususnya antara Negara Indonesia dan Negara Malaysia. Negara Indonesia dan Negara Malaysia memiliki perbatasan darat secara langsung. Aktifitas perdagangan memiliki peluang dan berpotensi besar dalam menghadapi MEA mengingat wilayah perbatasan berbatasan langsung dengan Negara Malaysia yang merupakan anggota dari negara-negara Asia Tenggara.

Hasil penelitian menunjukkan tidak sedikit barang berupa produk lokal dari perbatasan Indonesia diekspor ke Negara Malaysia. Salah satu produk lokal tersebut adalah produksi kerajinan anyaman tangan yang dihasilkan dari perbatasan Sajingan Besar yang di jual ke negara Malaysia. Produk kerajinan anyaman merupakan kearifan anyaman lokal Indonesia telah diwariskan secara turun temurun. Namun, peluang tersebut tidak diikuti dengan persiapan kualitas Sumber Daya Manusia (SDM) yang masih belum memiliki daya saing terutama di bidang pendidikan. Pola pikir masyarakat yang kurang inovatif juga semakin membuat keberadaan MEA tidak terlalu dirasakan Di Kabupaten Sambas. Keberadaan MEA belum diisi dengan sebuah kegiatan khusus dalam mempromosikan produk kerajinan tangan anyaman kepada pembeli. Selain itu kurangnya pembinaan dan pelatihan bagi para pengrajin anyaman tangan belum mendapatkan perhatian dari pemerintah sebagai ajakan promotor.

\section{Pemasaran Produktifitas Kerajinan Anyaman Tangan}

Eksistensi budaya dapat diturunkan sebagai identitas masing-masing kelompok masyarakat melalui kegiatan hiburan massa (Nye, 2008: 96). Terdapat event-event berbentuk pameran yang memasarkan produk-produk kerajinan anyaman tangan namun masih 
jarang masyarakat tertarik untuk membeli hasil produk. Masyarakat sekitar hanya sebatas melintas, kecuali ada hiburan seperti pameran yang diperankan oleh model dengan baju adat, kain khas daerah, kerajinan adat, pertunjukan seni budaya secara besar-besaran. Strategi formulasi mengembangkan pemasaran masih membutuhkan peran dari pemerintah agar pemasaran tidak sebatas agenda musiman, namun strategi untuk membuat masyarakat yang berkunjung lokasi tersebut tertarik untuk menemui tempat-tempat penjualanpenjualan produk-produk khas Kabupaten Sambas secara berkelanjutan.

Hasil penelitian menunjukkan bahwa telah ada rencana untuk membangun pasar desa, keberadaan pasar desa diyakini akan menjadi wadah bagi penjual untuk memperkenalkan kerajinan anyaman tangan, namun rencana tersebut belum dapat terealisasikan. Para pengrajin anyaman dari perbatasan Sajingan Besar Kabupaten Sambas mengikuti kursus pelatihan kerajinan anyaman di Negara Malaysia. Setelah itu mereka kembali menjual hasil kerajinan anyaman tangan tersebut di negara Malaysia. Hasil kerajinan anyaman tangan yang di bawa ke Negara Malaysia di modifikasi ulang sehingga bernilai jual yang lebih tinggi tinggi bahkan Negara Malaysia telah mengakuinya sebagai hak paten. Ilmu serumpun dan etnik negara Malaysia yang sama dengan Indonesia mengindikasikan telah terjadinya pengklaiman produk kerajinan tangan dari wilayah perbatasan Sajingan Besar Kabupaten Sambas yang dilakukan oleh Negara Malaysia untuk dijual ke pasar tingkat internasional.

Kesejahteraan suatu negara tergantung pada upaya pelayanan kepada publik (Mariana, 2011: 22). Tingkat kesejahteraan suatu wilayah diukur dari sumber daya dan kemampuan pemerintah dalam mengolahnya (Nye, 2008: 95). Kompetitor pasar adalah suatu persaingan dalam sistem perdagangan yang bertujuan untuk memenangkan pangsa pasar (Wicaksono dan Nuvriasari, 2012: 30). Perdagangan internasional membuka peluang pangsa pasar hasil produksi dalam negeri secara maksimal (Iskandar, 1999: 8). Kerajinan anyaman memiliki potensi pemasaran yang sangat besar karena pemesanan tidak hanya berasal dari dalam negeri namun juga dari luar negeri. Anyaman kerajinan memiliki peluang yang potensial karena negara luar sangat melirik kerajinan anyaman tangan dari perbatasan Indonesia. Pemasaran kerajinan di perbatasan Sajingan Besar Kabupaten Sambas hanya melalui pengepul (pemborong) kemudian dipasarkan ke museum. Selain itu pemasaran yang biasa dilakukan hanya menunggu jika ada pemesanan. Kebijakan pemerintah memiliki pengaruh besar bagi masyarakat perbatasan Sajingan Besar Kabupaten Sambas dalam menjalankan aktivitas pemasaran.

Hasil penelitian menunjukkan bahwa pemasaran di perbatasan Sajingan Besar Kabupaten Sambas juga terkendala karena belum ada kebijakan dari pemerintah untuk meresmikan PLBN Aruk di Kabupaten Sambas. Negara Malaysia juga belum meresmikan pintu masuknya karena infrastruktur jalan Indonesia di lokasi jalan Tanjung Sanjingan hingga kantor Camat Sajingan Besar belum selesai. Belum aktifnya PLBN Aruk yang terletak di Kabupaten Sambas meminimalisir potensi ekspor, padahal masyarakat Malaysia membutuhkan barang lokal milik Indonesia untuk memenuhi kebutuhannya terutama produk kerajinan tangan anyaman. Hal ini secara tidak langsung menjadi penghambat persaingan produk lokal dalam menghadapi MEA.Negara adalah sistem pemerintahan tertinggi dalam mengendalikan dan mengatur rakyatnya untuk mematuhi perundangundangan yang berlaku (Budiardjo, 2008:49). Negara memiliki kewenangan untuk mengatasi persoalan yang terjadi di kehidupan masyarakat (Soltau, 1961:1). Suatu negara tidak terlepas dari aktivitas perdagangan internasional terutama di wilayah perbatasan (Elyta, 2017: 1). Kebijakan yang ditetapkan dan dijalankan pemerintah mempengaruhi aktivitas di dalam kehidupan masyarakatnya. Hasil penelitian menemukan bahwa MEA hanya menguntungkan orang-orang yang memiliki modal besar. Pelaksanaan MEA dirasa belum memberikan kontribusi padahal penyelenggaraan MEA memiliki potensi besar mengingat wilayah perbatasan berbatasan langsung dengan Negara Malaysia. Kurang bersaingnya produk kerajinan anyaman tangan dalam menghadapi MEA karena pemerintah belum boleh menjadikan PLBN sebagai pintu ekspor sehingga proses ekspor harus melewati PLBN Entikong di Kabupaten Sanggau. Lalu lintas perdagangan belum memanfaatkan Pos Pemeriksaan Lintas Batas di Aruk karena PLBN Aruk belum dijadikan sebagai pintu resmi untuk mengekspor sehingga lintas batas untuk mengekspor kerajinan anyaman tangan lebih banyak melewati Entikong. Jauhnya jarak tempuh yang harus dilalui pengrajin anyaman tangan dalam mengekspor produkya menjadi kendala pengembangan produk anyaman tangan dalam menghadapi MEA.

\section{SIMPULAN}

Kerajinan anyaman tangan lokal merupakan warisan nenek moyang sebagai identitas suatu bangsa. Salah satunya adalah kerajinan anyaman tangan yang dihasilkan dari perbatasan Sajingan Besar Kabupaten Sambas. Kerajinan anyaman tangan tersebut memiliki potensi untuk dipasarkan ke hingga ke luar negeri. Hal tersebut dikarenakan letak wilayah Kecamatan Sajingan Besar Kabupaten Sambas berbatasan langsung dengan Negara Malaysia. Terdapat dua faktor penghambat pengembangan kerajinan anyaman tangan wilayah Kabupaten Sambas yaitu: 1) pola pikir masyarakat yang belum berkembang dan kurangnya lembaga pendidikan dan pembinaan di bidang pengrajin menyebabkan produktifitas kerajinan anyaman tangan sulit ber- 
kembang sehingga masyarakat belum memahami peluang dari terselenggaranya MEA; 2) pemasaran produk kerajinan anyaman tangan terkendala karena belum diresmikannya PLBN Aruk di Kabupaten Sambas. Pemasaran produk kerajinan anyaman tangan harus melalui PLBN Entikong, padahal lokasi perbatasan Kecamatan Sajingan Besar Kabupaten Sambas berdekatan dengan Negara Malaysia sebagai negara anggota ASEAN.

\section{DAFTAR PUSTAKA}

Badan Pusat Statistik Kalimantan Barat, (2015) Industri Besar dan Sedang Provinsi Kalimantan barat. Kalimantan Barat: Badan Pusat Statistik.

Badan Pusat Statistik Kabupaten Sambas, (2016) Kecamatan Sajingan Besar Dalam Angka. Sambas: Badan Pusat Statistik.

Budiardjo, M. (2008) Dasar-Dasar Ilmu Politik. Jakarta: Gramedia Pustaka Utama.

Elyta (2017) Perdagangan Gula Ilegal Di Wilayah Perbatasan Entikong Indonesia Dan Malaysia. Jurnal Sosiohumaniora. 19, (1) : $59-63$.

Grimes, R.L. (2014) The Craft of Ritual Studies. Journal Studies in Religion / Sciences Religieuses. 45(2), 250-252.
Iskandar, U. (1999) Kerjasama Internasional Menuju Pengelolaan Hutan Lestari. Yogyakarta: Bigraf Publishing.

Jeniarto, J. (2013) Diskursus Local Wisdom: Sebuah Peninjauan Persoalan-Persoalan. Jurnal Ultima Humaniora. 1(2), 15-27

MacIver, R.M. (1962) The Web of Government. New York: The Mac Millan Company.

Nurdin, F. (2011) Kedaulatan Di Wilayah Perbatasan. Bandung: Asosiasi Ilmu Politik Pontianak Indonesia.

Nye, J. (2008) Public Diplomacy and Soft Power. ANNALS, AAPSS 616 : 94-109

Rice, J. (2016) Professional Purity: Revolutionary Writing in the Craft Beer Industry. Journal of Business and Technical Communication. 30(2), 236-261.

Smith, S. (2016) Democracy and the Body Politic from Aristotle to Hobbes. Journals Permissions. DOI: $10.1177 / 0090591716649984$ : 1-30.

Soltau, R. F. (1961) An Introduction to Politics. London: Longmans.

Wicaksono, G. dan Nuvriasari, A. (2012). Meningkatkan Kinerja UMKM Industri Kreatif Melalui Pengembangan Kewirausahaan Dan Orientasi Pasar: Kajian Pada Peran Serta Wirausaha Wanita Di Kecamatan Moyudan, Kabupaten Sleman, Propinsi DIY. Jurnal Sosio Humaniora. 3(4), 27-39 